\title{
Sea-level pressure composite mapping in dendroclimatology: advocacy and an Agathis australis (kauri) case study
}

\author{
Anthony Fowler* \\ School of Geography and Environmental Science, The University of Auckland, Private Bag 92019, Auckland, New Zealand
}

\begin{abstract}
A typical starting point in dendroclimatological research is to statistically relate treering growth indices to local or regional climate variables (response function analysis). This sometimes leads to identification of links between tree growth and (often oscillatory) perturbations in atmospheric circulation, such as the El Niño-Southern Oscillation (ENSO) phenomenon. This approach relies on the researcher linking the (hopefully known) local-scale climate impacts of an oscillatory phenomenon with the response function results. A supplementary approach, advocated here, is to directly investigate relationships between tree growth and atmospheric circulation using composite mapping techniques. This paper demonstrates composite mapping, using the United Kingdom Meteorological Office gridded global monthly mean sea-level pressure (MSLP) data set and Agathis australis (kauri) tree rings. The results show that composite mapping is a powerful tool for tree-ring research, capable of identifying atmospheric circulation characteristics associated with wide and narrow tree rings, and helping to determine the potential of tree rings for reconstructing atmospheric circulation features. Results for kauri indicate that MSLP anomaly patterns associated with wide (narrow) tree rings have strong similarities to anomaly patterns associated with El Niño (La Niña) events. Relationships are strongest for wide tree rings and for the western pole of the Southern Oscillation. The results indicate that kauri is a strong ENSO proxy, with reconstruction potential strongest for the 6 mo from September to February.
\end{abstract}

KEY WORDS: Sea-level pressure $\cdot$ Composite mapping $\cdot$ Dendroclimatology $\cdot$ Kauri $\cdot$ Agathis australis

Resale or republication not permitted without written consent of the publisher

\section{INTRODUCTION}

Response function analysis is a common starting point for climate reconstruction from tree rings. This typically involves correlating tree-ring indices with local or regional precipitation and surface air temperature. The response function analysis then informs the development of transfer functions used to reconstruct local or regional climate, most probably focused on the same variables of precipitation and temperature.

Local temperature and precipitation are often forced by the strength and direction of prevailing winds. The latter are a function of the general atmospheric circulation and its quasi-periodic oscillatory patterns (QuasiBiennial Oscillation, North Atlantic Oscillation,
Southern Oscillation, etc.), which appear to be responsible for a large part of observed inter-annual to decadal-scale climate variability.

Where dendroclimatologists make the link between the climate signal in tree rings indicated by response functions and the known local climate impacts associated with one of the oscillatory patterns noted above, a plausible claim can be made that a tree-ring chronology has potential as a proxy for that oscillatory phenomenon. For example, response function analysis by Buckley et al. (2000) indicated that Agathis australis (D. Don) Lindley (kauri) tree rings are negatively correlated with both temperature and precipitation during the growing season. Fowler et al. (2000) subsequently identified the potential of kauri as a proxy for 
the Southern Oscillation (SO), based on the observation that the El Niño and La Niña phases of the SO respectively bring cool-dry and warm-wet conditions to the far north of New Zealand. Similar links to the SO have been made for several tree species, some of which have proceeded through to reconstruction attempts (e.g. Whetton \& Rutherford 1994, Stahle et al. 1998).

The procedure noted above for identifying potential tree-ring proxies for a specific quasi-periodic atmospheric oscillation is likely to work well where the relevant climate signal in the proxies is relatively strong and the local climate impacts of the oscillation are known. If the latter are unknown, then clearly no link between response functions and atmospheric circulation can be made. The approach also cannot identify links with regional-scale atmospheric circulation features of which we are unaware. Nor are we likely to identify complex relationships which are combinations of the influences of more than one source of atmospheric forcing. Under these circumstances, a more direct exploration of relationships between tree rings and atmospheric circulation is needed.

Hirschboeck et al. (1996) summarised 3 decades of evolution (to 1993) in studies directly linking tree rings to atmospheric circulation, beginning with Fritts (1965). They identified 4 method categories: eigenvectorbased (e.g. Fritts 1991); index-based (e.g. Stahle et al. 1998); event/weather-based (e.g. LaMarche and Hirschboeck 1984); and circulation map-based (e.g. Garfin 1998). Hirschboeck et al. (1996) noted a general under-utilisation of such methods by dendroclimatologists, often resulting in a missing process link between forcing atmospheric circulation and tree-ring data used for climate reconstruction. They attributed this under-utilisation in part to a lack of regional synoptic climatologies for the tree-ring chronology sites. This in turn was probably related to difficulties accessing high-quality, multi-decadal gridded atmospheric pressure data, which are required for the spatial analyses.

Although the mapping of global mean sea-level pressure (MSLP) has a long history, digital gridded MSLP data sets covering significant portions of the globe are a relatively recent development. Numerous errors and inconsistencies were encountered with the early data sets (Basnett \& Parker 1997), and it was not until the mid-1990s that methods (and data sources) had developed sufficiently for attempts to be made to combine the regional gridded data sets to produce a full global domain. The methods have evolved further (e.g. establishing background climatology, spatial interpolation techniques, error detection and correction), to the extent that dendroclimatologists now have access to high-quality global data sets that can be used for any tree-ring site. The data are freely available and easily accessed.
This study has 2 aims. The first is to advocate more widespread use of available MSLP data sets in dendroclimatology, focussing specifically here on the powerful, but relatively simple, method of MSLP composite mapping. This technique involves identification of common spatial patterns within the MSLP fields by producing an average composite map from all cases matching some selection criteria (e.g. frost rings). The composite map is typically expressed in terms of anomalies relative to some reference period, and then interpreted in terms of associated impacts on the frequency and/or strength of prevailing winds. This interpretation may help explain observed statistical relationships. The basic method is described in detail in Section 3, along with refined applications of composite mapping designed to (1) identify the potential of a proxy for reconstructing specific atmospheric phenomena; (2) assess the stationarity of relationships; (3) investigate the sensitivity of the proxy to forcing; and (4) refine our understanding of the tree-ring seasonal growth response window.

The demonstration of composite mapping (Section 4) uses a kauri master tree-ring chronology developed by Fowler et al. (2004). In that context, the study's second aim is to improve our understanding of kauri's potential as a palaeoclimate proxy, specifically for ENSO reconstruction. Note though that composite mapping is equally applicable to any tree-ring data, and indeed to any climate proxy that has precise calendar dating and has a resolution at annual or smaller scales. The technique is a supplement to traditional response function analysis, not a replacement.

\section{DATA}

\subsection{Gridded MSLP data (GMSLP2.1f)}

By the mid-1990s, a number of researchers had developed regional gridded MSLP data sets (Barnett et al. 1984, Harnack \& Harnack 1984, Jones et al. 1987, Jones \& Wigley 1988, Jones 1991), and attempts were being made to combine regional gridded data sets to produce a full global domain. One result of these activities was the United Kingdom Meteorological Office GMSLP2 data set. Blending diverse regional gridded data sets was a complex exercise, having to deal with myriad problems, including differences in grids and time periods, differences in how missing data were dealt with, and spatial inhomogeneities between data sets (Basnett \& Parker 1997). Several versions of GMSLP2 were produced as methods developed. GMSLP2.1f is the version of the data set used here. It is a gridded $5^{\circ}$ latitude by $5^{\circ}$ longitude, fully global data set. Resolution is monthly, and 
the period covered is 1871-1994. Basnett \& Parker (1997) evaluated GMSLP2.1f. They noted that the inclusion of quality-controlled observed data (since GMSLP2.1a) had improved reliability, but they also identified several weaknesses, including a lack of reliability in earlier decades, and the need to resort to climatology in data-sparse regions (especially in the Southern Hemisphere prior to 1951). See Basnett \& Parker (1997) for details.

\subsection{Kauri tree-ring data (AGAUm04a)}

The proxy data used to demonstrate composite mapping was the modern kauri master chronology (AGAUm04a) built by Fowler et al. (2004). Fowler et al. provided details of kauri, the data used to build the chronology, and the chronology construction method. For the 1871-1994 period (corresponding to GMSLP2.1f), the kauri master was built from at least 145 trees from 15 sites, growing throughout kauri's natural growth range in the far north of New Zealand (north of $38^{\circ} \mathrm{S}$ ). As such, the master chronology represents a regional-scale signal. Fowler et al. standardised the kauri tree-ring time series used to build AGAUm04a to maximise the climate signal, by removing radii- and tree-specific 'noise'. This resulted in a master tree-ring chronology with utility for investigating high-frequency climate forcing (e.g. ENSO), but lacking multi-decadal to century-scale information.

\subsection{Southern Oscillation Index (SOI)}

The ENSO component of this research was limited to the most commonly used index of the SO, the normalised pressure difference between Tahiti and Darwin. These are relatively long-term surface air pressure recording sites, near the respective poles of the SO across the equatorial Pacific Ocean. Specifically, monthly SOI values (1871-1994) published on the Internet by CSIRO Division of Atmospheric Research were used. These values are relative to a 1933-1992 base period. The data are continuous, missing data having been filled in with pressure data from nearby stations using the method of Konnen et al. (1998). Details can be found in Ropelewski \& Jones (1987) and Allan et al. (1991, 1996).

\subsection{Auckland Drought Index}

Fowler \& Adams (2004) modelled soil water for Auckland (near the middle of kauri's growth range) using a daily soil-water balance model (September
1900 to July 1998). Model mechanics, calibration, and verification were presented by Fowler (1999). Application of the model for long-term soil-water modelling (using mean potential evaporation) was described by Fowler (2002). Fowler \& Adams (2004) computed monthly mean soil-water deficits from the daily results and used a 1900-1994 subset for MSLP composite mapping. The same data set is used here.

\section{METHODS}

\subsection{Composite mapping}

Fig. 1 is a schematic of composite mapping, as applied to the GMSLP2.1f data set, using the analogy of a stack of cards. Gridded anomalies (Fig. 1C) were computed by subtracting monthly mean fields (Fig. 1B) from the original pressure data for each month (Fig. 1A), using the full available record to calculate mean fields. A 3-way split of the monthly anomaly data was then made, based on the value of a selected 'compositing key' variable. Fig. 1 demonstrates an unequal split using monthly values of the SOI. Averaging monthly pressure anomalies associated with low/ middle/high values of the SOI (Fig. 1E) results in El Niño/neutral/La Niña composites (Fig. 1F). Note the order-of-magnitude change in the scale of the anomalies plotted in Fig. 1F. Whereas December anomalies shown for 1994 (El Niño), 1990 (ENSO-neutral), and 1988 (La Niña) are $\pm 21 \mathrm{hPa}$, the mean anomalies for the El Niño and La Niña composites are less than 2 $\mathrm{hPa}$. This indicates subtle composite patterns, relative to inter-annual variability.

The SOI and drought analyses were based on monthly compositing, with each month allocated to a stack based on that month's value. For kauri, however, there was only 1 index value for each year, so the compositing was done based on whole 12 mo blocks. For example, if the tree-ring index for a given year corresponded to a high (wide ring) composite, then each month from September in the year growth started to the following August was allotted to the high composite stack. Equal 3-way compositing splits were used, except for the sensitivity analysis (see Section 3.4).

Monthly composites (Fig. 1F) were averaged across seasons (DJF, MAM, JJA, SON) and for the 6 mo window from September to February, the latter based on known persistent negative correlations between kauri tree rings and local monthly precipitation and surface air temperature over this interval (Buckley et al. 2000). High and low composite maps were then plotted, and spatial patterns were interpreted in terms of altered wind fields and associated local climate effects. 

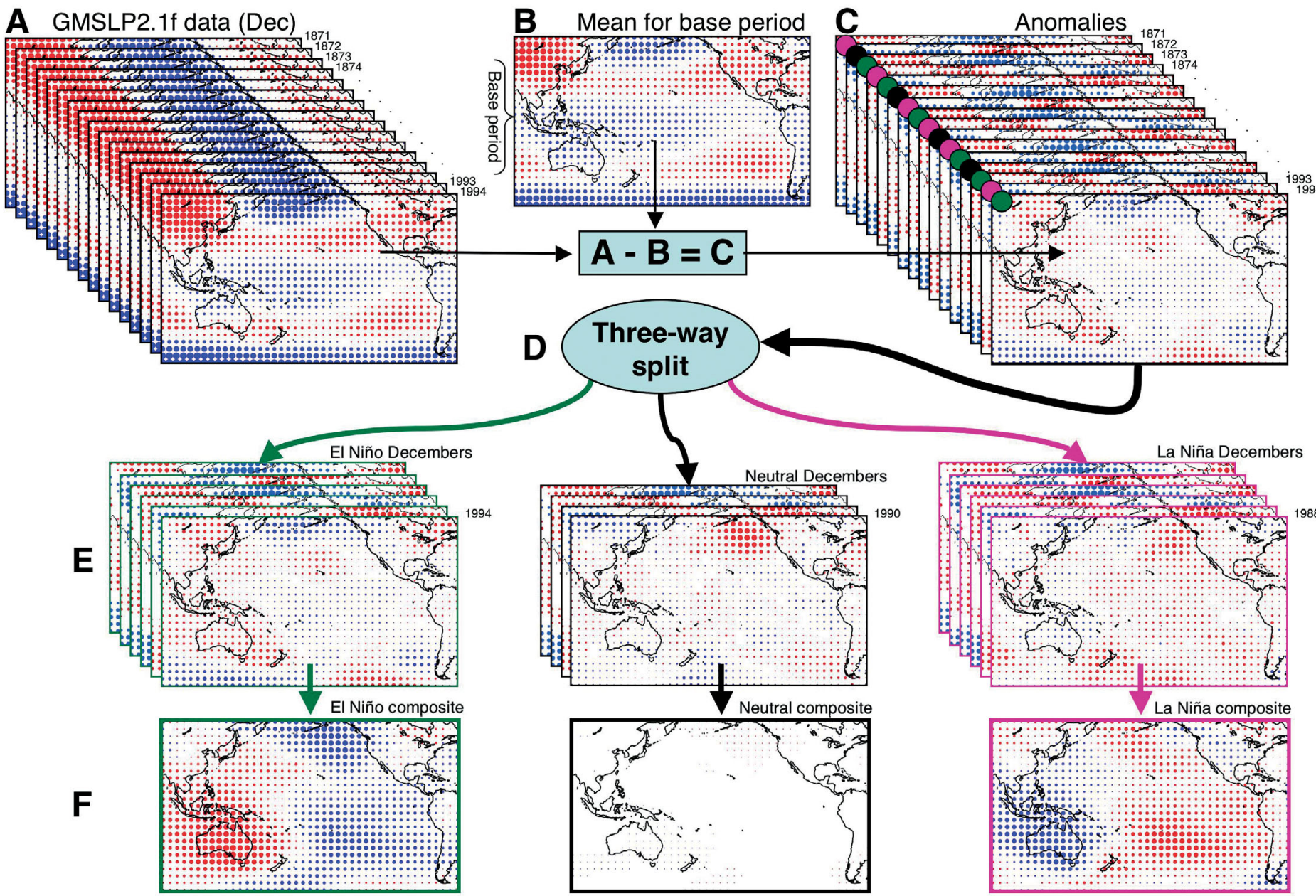

Fig. 1. Schematic of composite mapping using a card-stack analogy. Red (blue) dots indicate MSLP above (below) a standard atmospheric pressure of $1013.25 \mathrm{hPa}$ at sea level $(\mathrm{A}, \mathrm{B})$, or positive (negative) MSLP anomalies (C,E,F). The area of the dot indicates magnitude $\left( \pm 30 \mathrm{hPa}\right.$ for $\mathrm{A}, \mathrm{B}, \mathrm{C}, \mathrm{E}_{i} \pm 3 \mathrm{hPa}$ for $\left.\mathrm{F}\right)$. Only a small subset of cards are shown, and only the top card in each stack is accurate in the representation of MSLP anomalies. The coloured dots at the top-left of the 'anomalies' stack (C) indicate which cards go into each of the 3 composite stacks (based on a compositing key variable). The colour codes follow through to the arrows connecting (D) to (E) to (F)

\subsection{Identification of proxy reconstruction potential}

Composite mapping is primarily a visualisation tool, which exploits the ability of the human mind to recognise similarities and differences in complex visual patterns. For example, it is a simple task for us to recognise that the El Niño and La Niña patterns in Fig. 1F are near reversals of each other, but with subtle differences in both spatial pattern and intensity. Accordingly, the ENSO-reconstruction potential of kauri was primarily assessed by visual comparison of composite maps for wide and narrow tree rings with corresponding maps for El Niños and La Niñas. This subjective method was supplemented by objective spatial statistics, calculated over the Pacific domain shown in Fig. 1. The mean absolute anomaly (MAA) was used as an indicator of the overall strength of a composite map. When comparing maps, Pearson's product moment correlation coefficient
(R) was used to measure agreement in the spatial patterns, and mean absolute difference (MAD) as a measure of absolute error. Because of spatial autocorrelation, the statistical significance of the correlation and error statistics is best assessed using empirically derived sampling distributions (Wigley et al. 2000). Because this was not implemented in the compositing software, the cruder approach was adopted of assessing the statistical significance of the contingency tables associated with the 3-way splits of the monthly pressure data. A $\chi^{2}$ test was used with $\mathrm{p}<0.01$ as the significance threshold.

\subsection{Stationarity analysis}

The utility of a proxy for climate reconstruction is dependent in part on the stationarity of observed rela- 
tionships with climate. If the relationship is not stationary, a given proxy response (e.g. a wide tree ring) may have more than 1 possible climate cause, possibly resulting in an incorrect climate reconstruction. To investigate the stationarity of the kauri-climate response, the GMSLP2.1f gridded pressure data set was split into 3 similar sized subsets (1871-1910, 1911-1950, 1951-1995). Compositing analysis was then run on each of these subsets for both kauri tree rings and the SOI, using equal 3-way splitting. Stationarity was assessed by visually and statistically comparing the results.

\subsection{Sensitivity analysis}

Although basic composite mapping may indicate that a proxy carries a signal of some specific atmospheric forcing, more-refined analyses are needed to tell us whether the proxy signal is sensitive to the magnitude of forcing. The sensitivity of kauri tree rings to ENSO events was investigated here by repeating the SOI and kauri compositing analysis using 2 other 3-way composite splits, in which low/middle/high composite bins were 25/50/25 and $10 / 80 / 10 \%$ of the pressure data. Results were visually and statistically compared to determine whether the more extreme SOI and kauri composites had amplified anomaly patterns, whether the nature of any amplification was in a similar direction, and whether agreement between kauri and ENSO changed for more extreme cases.

\subsection{Refining understanding of proxy response}

Use of the 6 mo September-to-February compositing window was based on known persistent correlations between kauri tree rings and local climate variables. However, supplementing this with compositing analysis using seasonal and monthly windows can be a useful tool for refining the width of the sensitivity window and for investigating intra-annual variation in the strength of relationships. Both sources of information can be helpful when deriving transfer functions for climate reconstruction. Seasonal and monthly compositing on kauri wide and narrow tree rings was undertaken to this end, using equal 3-way compositing splits. Visual inspection of the multi-seasonal sequence of seasonal composite maps (from several seasons prior to growth to several seasons after) was then undertaken to identify lead and lag relationships, to determine when in the growing season relationships peak, and the consistency of relationships through the growing season. This was supplemented by monthly analyses. Note that the period of kauri growth is reasonably approximated by the standard austral spring through autumn seasons (SON, DJF, MAM) (Fowler et al. in press).

\section{RESULTS}

\subsection{Identification of proxy reconstruction potential}

SOI composite maps (Fig. 2A,B) show the characteristic MSLP anomaly pattern for El Niños of high pres-

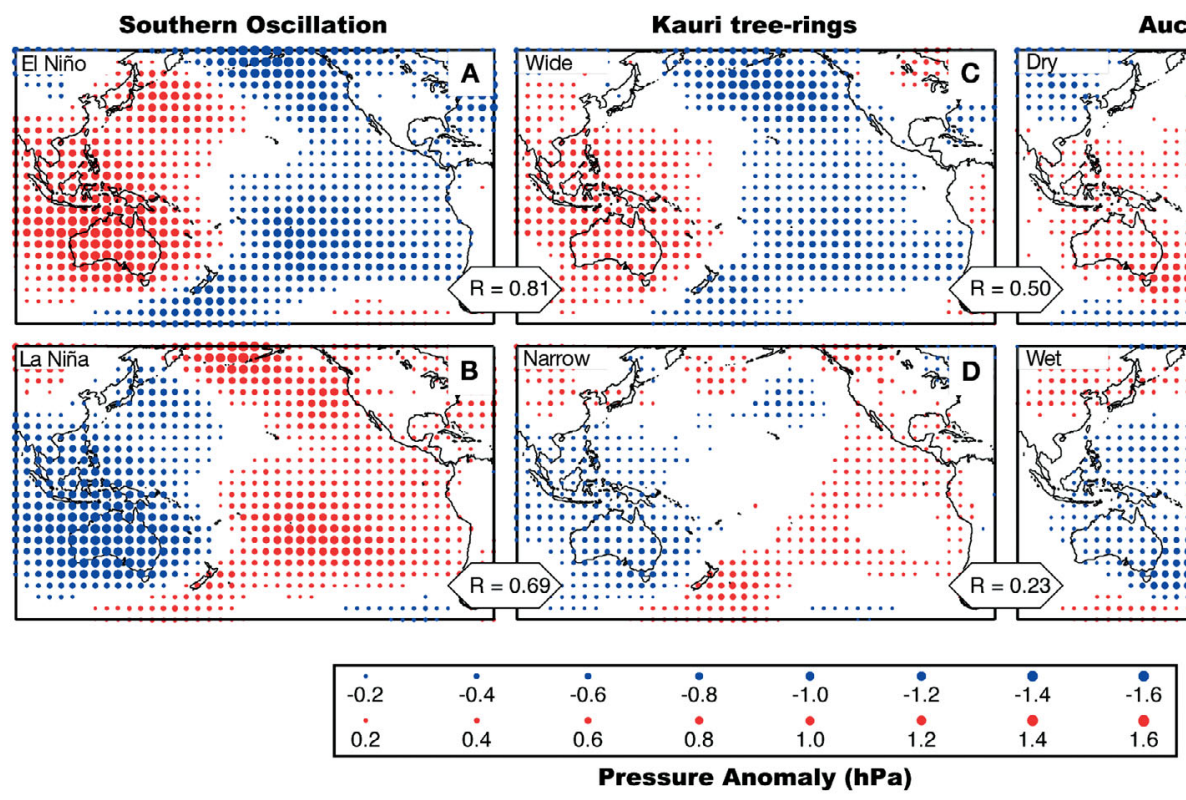

Fig. 2. September-to-February MSLP anomaly composite maps for 3 compositing key variables (SOI, kauri tree rings, Auckland drought). Composites were calculated for the common period 1901-1994 with equal 3-way splits into composite stacks (only high and low composites are shown) 
sure over Australia, extending into Southeast Asia and the Indian Ocean, with a boomerang-shaped lowpressure anomaly field in the eastern Pacific. The La Niña composite shows a near-opposite pattern $(\mathrm{R}=$ $-0.95)$, but it is slightly weaker (MAA $=0.33$ compared with $0.36 \mathrm{hPa}$ ). In contrast, although the composite maps for Auckland dry and wet phases (Fig. 2E,F) demonstrate some spatially extensive anomaly patterns (including an interesting apparent long-distance teleconnection to the north Pacific), the most obvious features are synoptic-scale patterns straddling New Zealand. The patterns are predominantly opposite $(\mathrm{R}=$ $-0.84)$, are similar in strength (MAA $=0.15 \mathrm{hPa}$ ), but are less than half the strength of the SOI composite maps.

MSLP composite maps for wide and narrow kauri tree rings (Fig. 2C,D) indicate MSLP pressure-anomaly patterns that are Pacific Basin wide. Wide rings are associated with positive anomalies over Southeast Asia and Australia, and also with negative anomalies extending in a boomerang shape from the northerncentral through the eastern to the southern-central Pacific (south and east of New Zealand). Narrow rings show a near-reversal of the anomaly patterns in a band extending from the Southeast Asian archipelago to the southern ocean, southeast of New Zealand. A weaker reversal to positive pressure anomalies is also apparent in the eastern Pacific, but this breaks down in the northern Pacific. The Pacific-wide strength of the anomaly patterns (MAA $=0.15$ and $0.22 \mathrm{hPa}$ ) is comparable to the Auckland drought composite maps, with wide rings having the stronger signal.

Comparison of the results for kauri with those for Auckland dry and wet phases indicates some agreement. (1) The $\chi^{2}$ significance tests showed that the association of wide (narrow) rings with dry (wet) phases was unlikely to have occurred by chance. (2) Some common features are apparent in the composite maps (e.g. the sign of anomalies over Australia and the Southeast Asian archipelago). (3) The overall Pacific-domain correlations are positive. However, the correlations are relatively weak, especially between the narrow kauri tree-ring composite and the composite for Auckland wet phases $(\mathrm{R}=0.23)$. There are also notable differences in the location centres of MSLP anomaly features, particularly the absence in the kauri composite maps of the synoptic-scale features over New Zealand that dominate both the dry and wet composite maps. On balance, it would appear that kauri has only limited potential as a drought proxy.

In contrast, the kauri composite maps exhibit strong similarities to those corresponding to ENSO phases. The agreement between the El Niño composite map (Fig. 2A) and that for kauri wide rings (Fig. 2C) is particularly striking. The kauri wide-ring anomalies are weaker, and there is no significant high-pressure anomaly east of Japan; but the patterns are otherwise nearly identical, especially in the Australasian region (including the demarcation between positive and negative anomalies). Anomaly patterns associated with narrow rings (Fig. 2D) agree well with the La Niña composite (Fig. 2B) in a band extending from Southeast Asia through to the southeast of New Zealand, but the representation of the positive-anomaly pattern in the eastern Pacific is weaker, especially in the north. A result is weaker Pacific-domain spatial statistics compared with the wide ring-El Niño comparison $(\mathrm{R}=0.69$ vs. $0.81, \mathrm{MAD}=0.25$ vs. $0.21 \mathrm{hPa}$ ).

\subsection{Stationarity}

The results of rerunning the ENSO and kauri compositing analyses on subsets of the MSLP data are shown in Fig. 3. Note that the top panels in Fig. 3 have more white space than the central panels, which in turn have more than the bottom panels. While some white space represents very small pressure anomalies, much is a consequence of the way in which missing data have been infilled with climatology (Section 2.1). Care is required to ensure that this artefact of the data gridding methodology is not misinterpreted as a change in the pressure-anomaly pattern prior to the second half of the 20th century. Missing data within a sub-period may also act to weaken an apparent anomaly. See Section 5.1 for further discussion of this issue.

The MSLP anomaly patterns associated with both ENSO phases were strongest in the late 20th century (Fig. 3C,I), even with the white space caveat noted above. The spatial patterns themselves were relatively consistent between periods, although the western pole was apparently more stable. Anomaly patterns in the North Pacific were much weaker in 1871-1910 (Fig. 3A,G), although this is likely to have been at least partly an artefact of infilling missing data. Patterns were weaker for both ENSO phases in the eastern Pacific in 1911-1950, especially off the South American coast. There was also a stronger positive-pressureanomaly field over New Zealand in 1871-1910, associated with La Niña (Fig. 3G).

Compositing results for wide kauri tree rings (Fig. 3D-F) show mostly stationary relationships. The anomaly pattern is qualitatively similar to that for El Niños for each time period and similarly peaks in the late 20th century. Similarities are most striking in the case of the western pole, although a notable southeast shift of the region of strongest positive anomalies in 1911-1950 (Fig. 3E) is not associated with a comparable change in the El Niño composite (Fig. 3B). The near-disappearance of any representation of the 

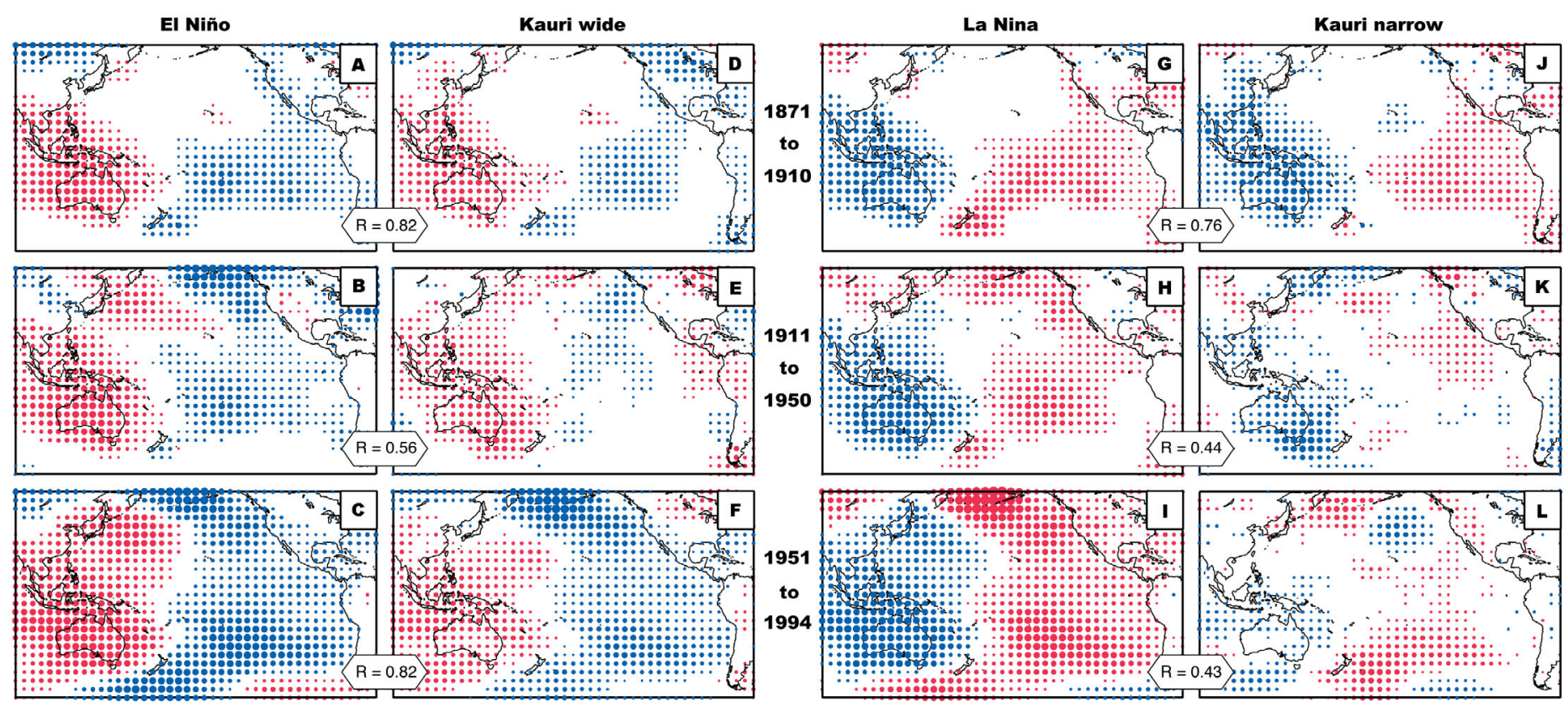

\begin{tabular}{|c|c|c|c|c|c|c|c|}
\hline-0.2 & -0.4 & -0.6 & -0.8 & -1.0 & -1.2 & -1.4 & -1.6 \\
\hline 0.2 & $\dot{0.4}$ & 0.6 & $\dot{0.8}$ & 10 & 1.2 & $\therefore 4$ & $\stackrel{\circ}{1.6}$ \\
\hline
\end{tabular}

Fig. 3. Investigation of the stationarity of relationships. September-to-February MSLP anomaly composite maps (SOI, kauri tree rings) are shown for 1871-1910, 1911-1950, and 1951-1994. Composites were calculated for each of these periods with equal 3-way composite splits (high and low composites shown). Mean pressure fields were recalculated for each time period (Step B in Fig. 1)

eastern pole of the SO (near Tahiti) in the 1911-1950 composite is a notable non-stationarity.

The compositing results for narrow kauri tree rings indicate a more complex situation. Although the pattern of positive eastern and negative western pressure anomalies is common to the 3 time periods (echoing La Niña), each is substantially different in detail. Western anomalies were very strong in 1871-1910, had a more southeasterly location in 1911-1950 (mirroring the previously noted wide-ring anomaly), and were weaker and less cohesive in 1951-1994. Eastern Pacific anomalies were strongest and most spatially coherent in 1871-1910, were near zero in the south Pacific in 1911-1950, then amplified in a band extending from the central southern Pacific through to the southeast of New Zealand in 1951-1994. Although the latter is consistent with the La Niña pattern, the concurrent weakness of the western anomalies resulted in an overall pattern that is clearly not consistent with the late 20th century strengthening of the La Niña pressure anomaly signal evident in Fig. 3I. It is noteworthy in this context that significance testing of the assignment of months to compositing stacks indicates non-significant relationships for the 1911-1950 and 1951-1994 comparisons. Note also that the spatial correlations are lower for all 3 time periods than the respective El Niño-kauri wide ring pairs.

\subsection{Sensitivity}

The upper panels in Fig. 4 show pressure composites (1871-1994) for kauri tree rings and ENSO using equal 3 -way splitting. These panels are essentially a pooled analysis of the data used in Fig. 3. They differ slightly from those presented in Fig. 2A-D because the latter were derived using a shorter time period (1901-1994). The middle and lower panels of Fig. 4 show the impacts of limiting the upper and lower composites to more extreme values of the compositing key (e.g. the 25 and $10 \%$ widest rings). All 6 comparisons shown in Fig. 4 had statistically significant contingency tables.

The results for the El Niño and La Niña compositing (Fig. 4A-C,G-I) show no significant changes to the spatial extent of the pressure fields. There are small changes at the edges of the main anomaly fields (e.g. near Hawaii) and in some peripheral regions. For example, positive anomalies near the North American Great Lakes are apparent with the more extreme El Niño composites. The main changes relate to intensifi- 

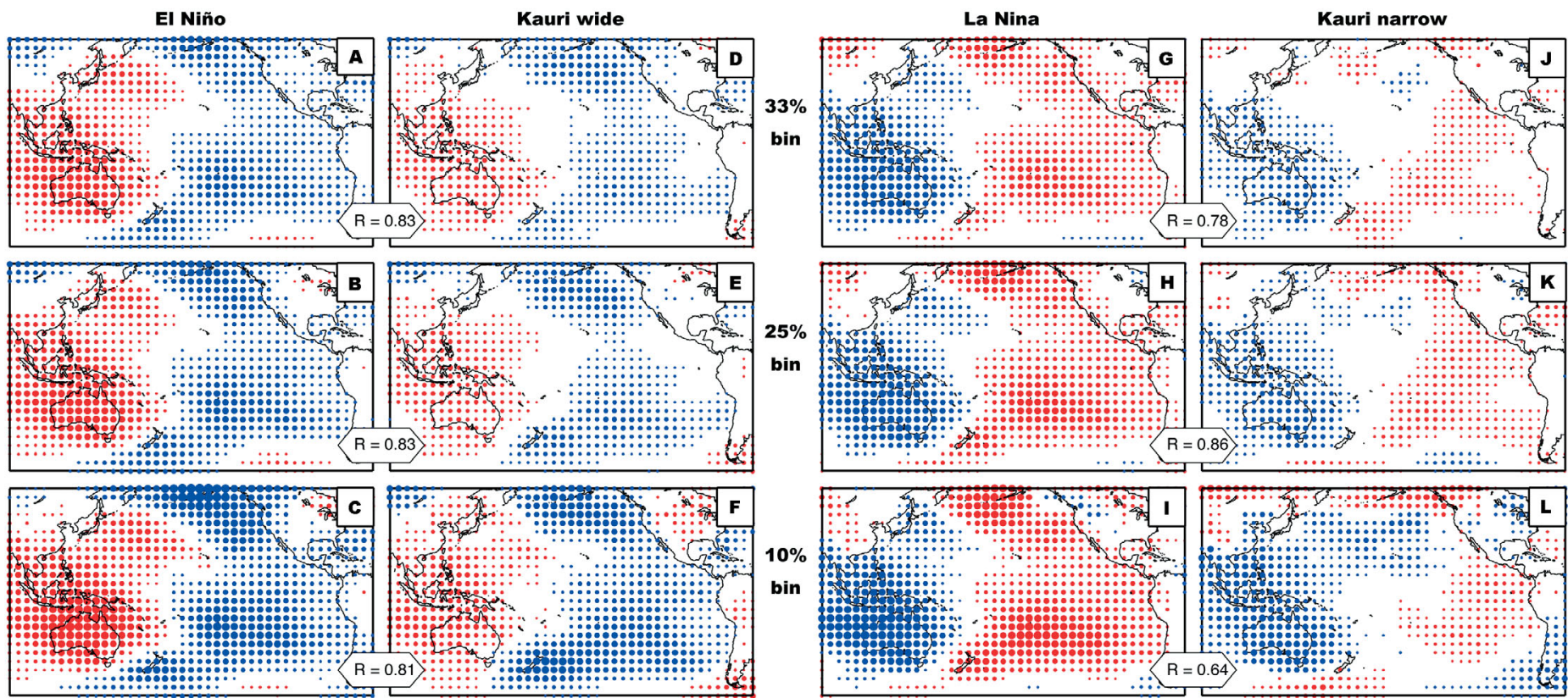

\begin{tabular}{|cccccccc|}
\hline-0.2 & -0.4 & -0.6 & -0.8 & -1.0 & -1.2 & -1.4 & -1.6 \\
0.2 & 0.4 & 0.6 & 0.8 & 0.0 & 1.2 & 1.4 & 1.6 \\
\hline
\end{tabular}

Pressure Anomaly (hPa)

Fig. 4. Sensitivity analysis. September-to-February MSLP anomaly composite maps (SOI, kauri tree rings) are shown for alternative 3-way compositing splits. The bin size referred to in the centre of the figure is the percentage of observations assigned to the high and low composite stacks. Lower bin percentages indicate that the relevant composite maps (shown) correspond to more extreme values of the SOI or kauri tree rings

cation of the main anomaly nodes. This was inevitable in the case of the ENSO composite nodes centred near Darwin and Tahiti, since the SOI was used as the compositing key, but there is also significant intensification in the northern Pacific and near New Zealand.

For the kauri wide tree-ring composites (Fig. 4D-F), the main effect of restricting the analysis to wider rings is a strengthening of the magnitude of the anomalies in both the north and south Pacific (south of Alaska and near New Zealand). There is also a westward shift in the location of the strengthened southern anomaly node, from east of to over New Zealand. For the widest $10 \%$ of tree rings (Fig. $4 \mathrm{~F}$ ), there is also a northwards expansion of the positive anomalies (e.g. to over Japan) and an eastwards expansion of negative anomalies (to the western coastline of the Americas). Of particular importance, in terms of ENSO reconstruction potential, the anomaly patterns show an amplification of the Tahiti-Darwin contrast.

The narrow ring composite plots (Fig. 4J-L) indicate that restricting the analysis to increasingly narrow tree rings results in both an expansion and intensification of the western zone of negative pressure anomalies. However, the eastern Pacific situation is confused. Small positive pressure anomalies persist over Tahiti, but do not increase in intensity. There is an intensification of positive anomalies to the south of New Zealand, and a negative anomaly develops over the North American Great Lakes, but neither of these features is evident in the La Niña composite plots. Overall, there is an amplification of the Tahiti-Darwin contrast, but this is entirely related to the western pole of the SO.

Correlations between map pairs in Fig. 4 do not increase as compositing is applied to more extreme cases, reflecting relatively minor adjustments to spatial patterns. However, the strength of the anomaly signal (MAA) increases for all 4 composite key variables - by about $60 \%$ for the ENSO composites and about $100 \%$ for the kauri composites. The MAA increase for the kauri composites partly relates to increased coincidence of ENSO events with more extreme kauri tree rings. This is confirmed by inspection of the compositing key contingency tables (not shown). For example, the joint occurrence of El Niños and kauri wide rings is $40 \%$ higher than expected by chance for equal 3-way splitting (33\% bin), increasing to 60 and $120 \%$ for the 25 and $10 \%$ bins, respectively. The corresponding figures for joint occurrence of La Niñas and narrow rings are 20 to $30 \%$ lower. The fact that the proportional MAA increases for kauri are higher than for ENSO suggests that more extreme tree rings are also associated with more extreme ENSO events. This was demonstrated by regression analysis (Fowler et al. 2000). 


\subsection{Refining understanding of proxy response}

Seasonal compositing analyses show that the compositing patterns develop to maturity and then decay over a period of 5 seasons (Fig. 5). Monthly analyses (not shown) indicate a clear beginning to the pressureanomaly patterns in March prior to growth, for both wide and narrow tree-ring composites, but the situation at the end of the growing season is ambiguous. There is some evidence of a continuation of the patterns into the following JJA, but monthly patterns are variable and are inconsistent between wide and narrow tree rings.

The broad seasonal patterns are reasonably consistent for wide and narrow tree rings. A weak ENSO pattern is apparent by the prior MAM (Fig. 5A,F), dominated by pressure anomalies centred near southeast Australia. This southeast Australia focus for the western anomalies persists until SON, after which they weaken and shift northwards. Evolving patterns in the eastern Pacific also exhibit close mirroring. However, there are also interesting seasonal nuances. For example, the positive anomalies associated with wide rings peak in JJA prior to growth, with a notable expansion across New Zealand (Fig. 5B). At this time the narrow tree-ring composite pattern (Fig. 5G) is still strengthening and negative anomalies do not extend east of Australia. (The JJA pattern for wide tree rings is consistent with results for El Niño compositing.) Also noteworthy are the strong negative North Pacific pressure anomalies in DJF for wide kauri tree rings (Fig. 5D), and the strong positive anomalies south of New Zealand, and also near Canada and Alaska, associated with narrow tree rings (Fig. 5I). These 3 features are apparent in the September-to-February compositing analyses, but Fig. 5 clearly indicates that they are season-specific features.

\section{DISCUSSION}

\subsection{Composite mapping}

Composite mapping is a powerful tool that has the potential to bring an atmospheric process perspective to palaeoclimate research. Because of progress in recent years in developing quality-controlled, globally
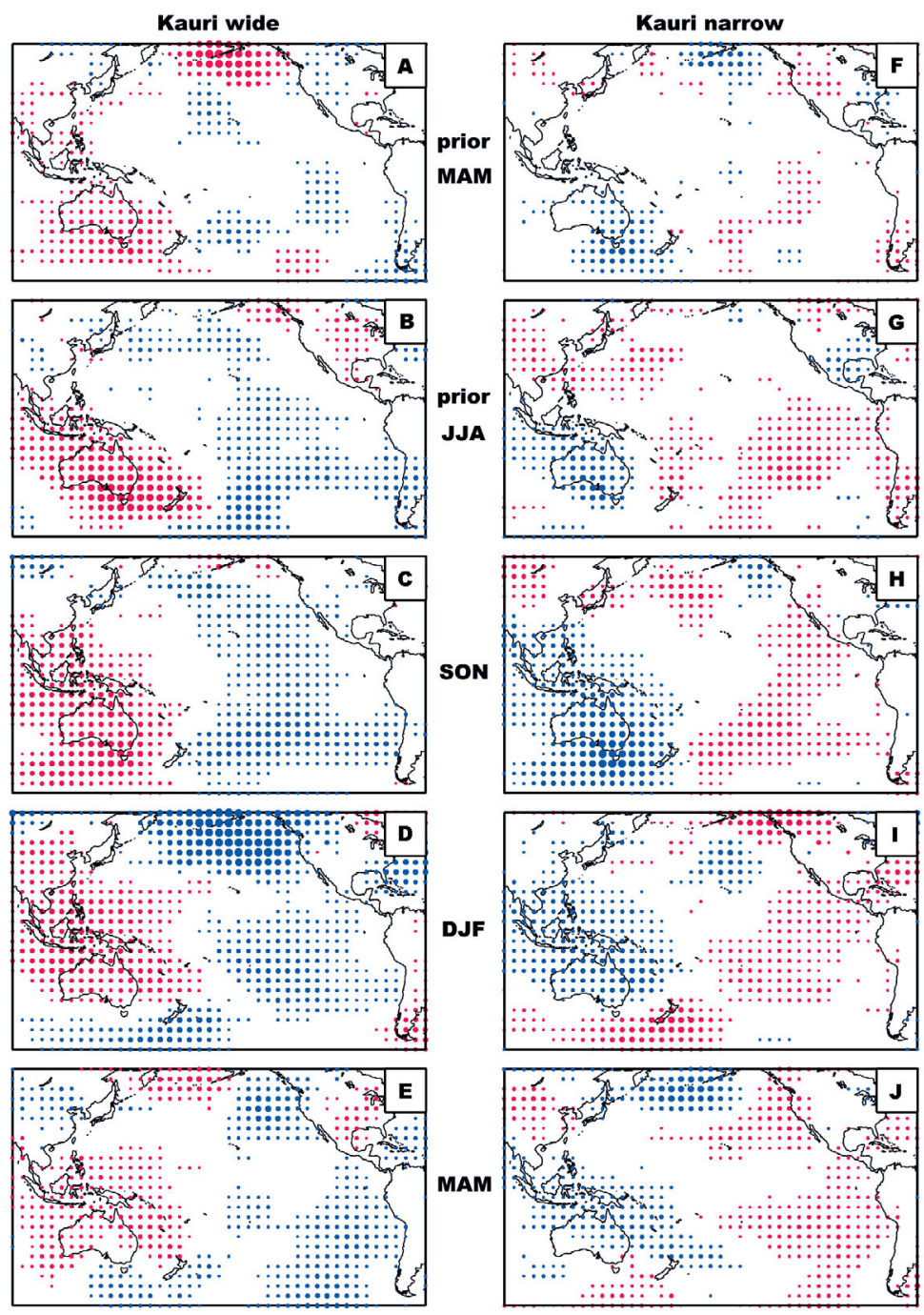

\begin{tabular}{|cccccccc|}
\hline-0.2 & -0.4 & -0.6 & -0.8 & -1.0 & -1.2 & -1.4 & -1.6 \\
0.2 & 0.4 & 0.6 & 0.8 & 10 & 1.2 & 1.4 & 1.6 \\
\hline
\end{tabular}

Pressure Anomaly (hPa)

Fig. 5. Use of composite mapping to refine understanding of the kauri sensitivity window (window width, inter-seasonal variation in relationship pattern and strength, seasonal evolution). 'Prior' denotes seasons before growth commences in September. Only seasons with a discernable kauri ENSO-like composite pattern are shown

gridded MSLP data sets, the free and easy access to those data, and the conceptual simplicity of the composite mapping method, widespread application of composite mapping as a data exploration tool is feasible. However, powerful and easily accessed tools are often easily abused, and composite mapping provides ample opportunity for this. Having advocated its use in palaeoclimate research, I discuss here 3 specific recommendations designed to reduce the likelihood of errors of application and/or interpretation. Specifically, we need to understand, and allow for (1) the evolving 
quality through time of the underlying gridded MSLP data; (2) the limits of compositing analysis in the case of complex relationships; and (3) the significance of inter-annual variability.

As detailed in Section 2.1, the quality of gridded MSLP data deteriorates further back in time in a spatially uneven manner. The subsequent infilling of missing data with climatology (as in GMSLP2.1f) is necessary, but has important implications. As the amount of missing data increases the magnitude of any composite pressure anomaly may be reduced. This is because some of the anomaly 'signal' may be replaced by a mean value (in the worst case of all infilled data, all 3 composite stacks have the same zero-anomaly field). Consequently, even if 2 locations have identical actual pressure anomaly signals, the one with more missing data would probably yield lower absolute values in the compositing analysis. This has 2 important effects. (1) Composites derived using periods that contain much missing data (e.g. the 1871-1994 El Niño composite in Fig. 4A) are likely to have a generally subdued signal, which is also regionally biased. (2) It makes stationarity analysis fraught with difficulty. It is plausible, for instance, that the general intensification of signal in Fig. 3A-C is an artefact of missing data infilling, rather than a real intensification of the MSLP anomaly pattern associated with ENSO. Resolving such problems would require more sophisticated analytical methods.

Compositing analysis is effective where there is a single dominant MSLP anomaly pattern associated with the compositing key variable (e.g. tree rings). It is less helpful, and may be useless, where the situation is more complex. Consider, for example, a hypothetical case where narrow tree rings for some tree species are caused by early-season cold or by late-season drought. Each situation may be associated with a distinct MSLP anomaly pattern, but these might be unrelated. Compositing would combine these unrelated anomaly fields, giving a bastardised result that represents neither case. Such situations can be dealt with, but doing so goes beyond the simple application of compositing advocated here. Fortunately, complex situations can be identified by examination of pressure anomalies on an event basis (e.g. using simple movie loops). This is advisable in all cases. Problems were not encountered in the case of kauri.

A critical point was made in Section 3.1, concerning the order of magnitude difference in the size of individual monthly pressure anomalies $( \pm 21 \mathrm{hPa})$ and anomalies typically associated with composites $(< \pm 2 \mathrm{hPa})$. Because of this, compositing is sensitive to outliers, especially as the number of cards in a composite stack is reduced to single figures. This was why intervals smaller than 40 yr were not investigated in Section 4.2 (ca. 13 card stacks) and the reason for resorting to the full GMSLP2.1f data set in the sensitivity analysis (Section 4.3). A solution to this issue is to use a measure of central tendency that is less sensitive to outliers than the simple mean, such as a scaled mean (Brown \& Hall 1999) or the median. Otherwise it is advisable to ensure stacks are at least in double figures. Again, it is possible to check for outliers using event-based inspection of anomalies.

\subsection{Kauri as an ENSO proxy}

\subsubsection{Empirical relationships and reconstruction potential}

From the perspective of reconstructing ENSO, a perfect proxy would consistently echo changes in the gridded anomaly fields associated with ENSO phases. Kauri wide rings approach this in terms of the western pole of positive pressure anomalies and the late 20th century intensification. They are somewhat compromised by the fact that some of the time (e.g. 1911-1950, Fig. 3E) wide rings are predominantly associated with the western positive pressure anomalies, at a time when El Niños retain the dual-pole anomaly pattern (Fig. 3B). For narrow kauri tree rings, the situation is more complex. Only the 1871-1910 composite (Fig. 3J) is close to the reconstruction ideal of narrow tree rings associated with opposite anomaly poles. The 1911-1950 and 1951-1994 composites are incomplete representations of the La Niña pattern (Fig. 3H,I).

The strengthened 1951-1994 El Niño composite (Fig. 3C) coincided with a similar strengthening of the wide kauri tree-ring composite (Fig. 3F), indicating stationarity in the relationship between wide rings and El Niño. In contrast, the similar strengthening of the La Niña composite pattern (Fig. 3I) did not coincide with a strengthening for the narrow ring composite. This is the most striking stationarity issue arising from the results presented, suggesting a possible breakdown in the relationship between La Niña and narrow kauri tree rings in the second half of the 20th century. It is possible that factors other than La Niña became newly or more influential in generating conditions unfavourable to kauri growth.

Sensitivity and other analyses (Section 4.3) indicated that both wide and narrow kauri tree rings carry useful information about ENSO magnitude (in addition to event occurrence). In the case of narrow rings, this is limited to the western pole, but for both wide and narrow tree rings there is an increase in the TahitiDarwin contrast. This implies that the full range of kauri tree rings should be a useful SOI proxy, although the western dominance in the case of narrow rings may be an issue. 
Seasonal and monthly compositing (Section 4.4) identified a 5-season window of kauri sensitivity to ENSO, extending from MAM prior to growth to the following MAM, with the strongest response in the middle 3 seasons (JJA-DJF). Wide and narrow rings show similar (reversed) patterns, although the JJA anomaly pattern is weaker in the case of narrow rings. The general pattern is consistent with the known genesis and life cycle of ENSO events and with teleconnections to New Zealand climate (Mullan 1995). It also indicates that the greatest potential for ENSO reconstruction is likely to be the 6 mo period starting in September, or possibly the 9 mo period starting in July. If a 12 mo reconstruction is required, then the period July to May would be best, since the MSLP anomaly patterns for MAM at the end of the growing season (Fig. 5E,J) are more ENSO-like than those for MAM prior to growth (Fig. 5A,B), especially for the eastern pole.

\subsubsection{Process links}

The kauri growth region in the far north of New Zealand lies between the pressure-anomaly features centred over Australia and Indonesia, and those (of opposite sign) to the southeast of New Zealand. This means that wide and narrow kauri tree rings are associated with significant and opposite wind field perturbations. For example, in the case of wide rings, the pressure-anomaly fields shown in Fig. 3 would be expected to cause an increase in the frequency and/or strength of southwesterly winds, bringing relatively cool-dry conditions. The associated pressure anomaly fields for narrow rings would be expected to result in warm-wet conditions. These relationships agree well with previously identified negative correlations of kauri growth to growing-season precipitation and surface air temperature (Buckley et al. 2000). Moreover, having identified the dominant atmospheric circulation anomaly features causing the cool-dry or warm-wet conditions, it can be deduced that it is probably conjoint warmth and wetness (or coolness and dryness) that is important. The ENSO connection to kauri growth then follows from recognition of the similarity in the respective MSLP anomaly fields.

Seasonal compositing analysis further refined understanding of atmospheric process links and facilitated the generation of hypotheses about causal mechanisms. For example, it is evident from Fig. 5 that atmospheric circulation characteristics immediately prior to and for the first 6 mo of growth (JJA, SON, DJF) are most critical for wide kauri tree rings. Favourable conditions and possible mechanisms include: JJA anticyclonic conditions centred over southeastern Australia and across New Zealand (settled, sunny, dry);
SON anticyclonic conditions centred over Australia and low pressure east of New Zealand (more southerly winds, more sunshine hours, low rainfall); and DJF anticyclonic conditions centred over northern Australia and low pressure southeast of New Zealand (more southwesterly winds, more sunshine hours, lower rainfall). The narrow tree-ring situation is largely the reverse in SON and DJF, but is unclear in JJA.

The link between kauri tree rings and pressure fields up to 2 seasons prior to the beginning of growth is unexplained, but not surprising. It may relate to preconditioning of kauri at the end of the previous growing season or during dormancy (i.e. affects on the tree that influence subsequent growth), pre-conditioning of the environment (e.g. soil-wetness conditions leading into the growing season), or it may simply reflect ENSO persistence. The latter relates to ENSO being strongly coupled to the annual cycle, with both El Niño and La Niña events tending to develop during MAM and usually lasting a year or more (Diaz \& Kiladis 1992).

\section{CONCLUSIONS}

This research has demonstrated that MSLP composite mapping can be a powerful palaeoclimate research tool. It can help identify links between a proxy and possible atmospheric forcing (through recognition of similarities in the gridded anomaly fields), and it can lead to hypotheses concerning potential forcing mechanisms (via interpretation of associated windfield anomalies). The latter may in turn help explain observed statistical relationships between the proxy and local climate. Refined application of compositing can be used to investigate the stationarity of relationships (by compositing over different time periods) and proxy sensitivity (by changing the compositing 3-way split). It can also help refine understanding of the proxy response window, both in terms of timing (start, end, width) and intra-window variability in relationship patterns and strength. However, care is required in application of the method and interpretation of the results, due to the evolving quality (including spatial bias) of the gridded MSLP data, the possibility of multiple atmospheric forcing modes, and the relatively subtle nature of anomaly fields (relative to inter-annual variance).

Composite mapping applied to kauri tree rings showed that wide and narrow rings are associated with MSLP anomaly patterns across the Pacific Basin. Patterns for wide and narrow rings approximately mirror each other, although those for wide rings are somewhat stronger and are more spatially coherent. Both are associated with an east-west oscillatory pattern, 
with opposite poles centred in the Indonesia-Australia region and in the eastern Pacific. These are very similar in pattern to those associated with ENSO, although the western pole of the SO appears to be more strongly linked to kauri growth than the eastern pole. The similarity between the anomaly patterns associated with El Niño and wide kauri tree rings is particularly striking, and all results suggest that wide rings are likely to be more reliable for reconstructing El Niño than narrow rings for reconstructing La Niña events. The links between ENSO and kauri growth persist over a 5-season period, starting in March prior to growth starting, peaking in the austral spring and summer (September to February). The latter period therefore has greatest potential for ENSO reconstruction, although reconstructions for periods of up to 12 mo are feasible (coupled to the ENSO cycle).

Acknowledgements. Financial support for this research was provided by the New Zealand Foundation for Research, Science and Technology (FRST contract UOAX0011) and by the Royal Society of New Zealand (Marsden Fund grant UOA108). I thank the United Kingdom Meteorological Office (Hadley Centre) for access to the GMSLP2.1f data set, accessed through the British Atmospheric Data Centre. SOI data was obtained from the CSIRO Atmospheric Research web site. Five anonymous reviewers provided helpful comments that improved the quality of the manuscript.

\section{LITERATURE CITED}

Allan RJ, Nicholls N, Jones PD, Butterworth IJ (1991) A further extension of the Tahiti-Darwin SOI, early ENSO events and Darwin pressure. J Clim 4:743-749

Allan RJ, Lindesay JA, Parker DE (1996) El Niño Southern Oscillation and climatic variability. CSIRO Publications, Melbourne

Barnett TP, Brennecke Kauri, Limm J, Tubbs AM (1984) Construction of a near-global sea-level pressure field. SIO Reference Series 84-7, Scripps Institute of Oceanography, La Jolla, CA

Basnett T, Parker D (1997) Development of the Global Mean Sea Level Pressure Data Set GMSLP2. Climate Research Technical Note 79, Hadley Centre, United Kingdom Meteorological Office, Bracknell

Brown TJ, Hall BL (1999) The use of $t$ values in climatological composite analyses. J Clim 12:2941-2944

Buckley B, Ogden J, Palmer J, Fowler A, Salinger J (2000) Dendroclimatic interpretation of tree-rings in Agathis australis (kauri). 1. Climate correlation functions and master chronology. J R Soc NZ 30:263-275

Diaz HF, Kiladis GN (1992) Atmospheric teleconnections associated with the extreme phase of the Southern Oscillation. In: Diaz HF, Markgraf V (eds) El Niño: historical and paleoclimatic aspects of the Southern Oscillation. Cambridge University Press, Cambridge, p 7-28

Fowler AM (1999) Potential climate change impacts on water resources in the Auckland region (New Zealand). Clim
Res 11:221-245

Fowler AM (2002) Assessment of the validity of using mean potential evaporation in computations of the long-term soil water balance. J Hydrol 256:248-263

Fowler A, Adams K (2004) Twentieth century droughts and wet periods in Auckland (New Zealand) and their relationship to ENSO. Int J Climatol 24:1947-1961

Fowler A, Palmer J, Salinger J, Ogden J (2000) Dendroclimatic interpretation of tree-rings in Agathis australis (kauri): 2. Evidence of a significant relationship with ENSO. J R Soc NZ 30:277-292

Fowler A, Boswijk G, Ogden J (2004) Tree-ring studies on Agathis australis (kauri): a synthesis of development work on Late Holocene chronologies. Tree-Ring Res 60:15-29

Fowler A, Lorrey A, Crossley P (in press) Seasonal growth characteristics of kauri. Tree-Ring Res

Fritts HC (1965) Tree-ring evidence for climatic changes in western North America. Mon Weather Rev 93:421-443

Fritts HC (1991) Reconstructing large-scale climatic patterns from tree-ring data: a diagnostic analysis. University of Arizona Press, Tucson, AZ

Garfin GM (1998) Relationships between winter atmospheric circulation patterns and extreme tree growth anomalies in the Sierra Nevada. Int J Climatol 18:725-740

Harnack J, Harnack RP (1984) A Southern Hemisphere sea level pressure data set for use in climate studies. J Climatol 4:187-204

Hirschboeck KK, Ni F, Wood ML, Woodhouse CA (1996) Synoptic dendroclimatology: overview and outlook. In: Dean JS, Meko DM, Swetnam TW (eds) Tree rings, environment, and humanity. Proc Int Conf, Tucson, AZ, 17-21 May, 1994, p 205-223 (available at: http://radiocarbon.org/Pubs/treh.html)

Jones PD (1991) Southern Hemisphere sea level pressure data: an analysis and reconstructions back to 1951 and 1911. Int J Climatol 11:585-607

Jones PD, Wigley TML (1988) Antarctic gridded sea level pressure data: an analysis and reconstruction back to 1957. J Clim 1:1199-1220

Jones PD, Wigley TML, Briffa KR (1987) Monthly mean pressure reconstructions for Europe (to 1780) and North America (to 1858). DoE Technical Report TR037, US Department of Energy, Carbon Dioxide Research Division, Washington, DC

Konnen GP, Jones PD, Kaltofen MH, Allan RJ (1998) Pre-1866 extensions of the Southern Oscillation Index using early Indonesian and Tahitian meteorological readings. J Clim 11:2325-2339

LaMarche VC Jr, Hirschboeck KK (1984) Frost rings in trees as records of major volcanic eruptions. Nature 307:121-126

Mullan AB (1995) On the linearity and stability of Southern Oscillation-climate relationships for New Zealand. Int J Climatol 15:1365-1386

Ropelewski CF, Jones PD (1987) An extension of the TahitiDarwin Southern Oscillation Index. Mon Weather Rev 115:2161-2165

Stahle DW, D'Arrigo RD, Krusic PJ, Cleaveland MK and 11 others (1998) Experimental dendroclimatic reconstruction of the Southern Oscillation. Bull Am Meteorol Soc 79: $2137-2152$

Whetton P, Rutherford I (1994) Historical ENSO connections in the eastern hemisphere. Clim Change 28:221-253

Wigley TML, Santer BD, Taylor KE (2000) Correlation approaches to detection. Geophys Res Lett 27:2973-2976

Submitted: December 16, 2004; Accepted: May 16, 2005

Proofs received from author(s): June 10, 2005 